\title{
A Review of Thailand's Transport Master Plan for Regional Cities
}

\author{
Peraphan Jittrapirom $^{1,2^{*}}$ and Sittha Jaensirisak ${ }^{3}$ \\ 1 National Institute for Environmental Studies \\ 2 Nijmegen School of Management, Radboud University \\ 3 Civil Engineering Department, Ubon Ratchathani University \\ * Corresponding Author, Email: peraphan.j@gmail.com
}

Received: July 26, 2019 Accepted: December 13, 2019

Keywords: Planning, Regional City, Developing Country

\begin{abstract}
Formulating a transport master plan for a regional city in a developing country can be a challenging task. Regional cities are often lacking financial resources or have limited expertise in the field of transport. Consequently, they are more likely to experience transport problems as they undergo expansion. The tradition of transport planning for regional cities in Thailand began as recently as 1994 with the master plan for Chiang Mai city. Since then, there has been a broad implementation of transport planning across the country, driven by the Office of Traffic and Transport Policy and Planning (OTP). As a result, most Thai cities now have a transport master plan. In this paper, we describe Thailand's process in formulating and implementing its master plans across the regional cities. We provide three case studies to illustrate the process in practice. The study reveals some lessons learned that could be useful to identify critical planning and governance mechanisms for other developing countries, especially those in the same region, such as Vietnam, Cambodia, and Myanmar.
\end{abstract}

\section{INTRODUCTION}

Transport has an essential role in ensuring the vitality of a city. However, the urban transport system in many cities is also a significant contributor to the degradation in the quality of life (Banister, 2001; Black, 2010; Greene \& Wegener, 1997).These detrimental effects of transport point toward the need for better planning and management of such a system.

Research has predominantly focused on planning and policy options, or tools and assessment methods for the decision-making process. For example, Nakamura, Hayashi, and May (2004) and KonSULT (2005) review the impacts of policy instruments in different cities. Shepherd et al. (2006) and Zhang et al. (2006) research on designing transport strategies. May (1991), Geerlings and Stead (2003), and Potter and Skinner (2000) look into the principles of integration. Finally, the decision support system is dealt with in the works of Miyamoto et al. (1996) and Ülengin et al. (2007). However, the contexts of these studies are developed countries.

There is an increasing amount of literature that seeks to contribute to urban transport planning practice in developing countries. In particular, by providing a record of on-going practices as evidence for comparison and 
improvements. For example, Volpe Martincus, Carballo, and Cusolito $\underline{(2017)}$ evaluates Peru's road program in its capacity to deliver promised export expansion and job creation, Walters (2013) provides an overview of South Africa public transport policy and its policy framework, and Figueroa (2013) traces back the dynamic change of Santiago's transport policy over four decades. For Thailand, there are also some studies, such as Daniere $\underline{(1995)}$ and Jaensirisak (2008), that review transport planning for Bangkok. However, to the best of our knowledge, there is still a lack of literature documenting cases from the regional cities within the south-east Asia region.

This study aims to examine Thailand's urban master planning process for regional cities and how the planning process is implemented. The study outcomes will enable a comparison between Thailand's process with other international examples. Additionally, the case study in Thailand can highlight the potential challenges for other developing countries in planning and policymaking. Despite the government's continued efforts, Thailand is well-known for its high rate of road accidents (World Health Organization, 2015, 2018; Un-Habitat, 2013). The possible improvements and lessons learned from such cases can be useful for other developing countries in the same region, such as Vietnam, Cambodia, and Myanmar.

We introduce the background and motivation of the study in this section. Next, we outline the methodology of the study in Section 2. We then describe the Office of Traffic and Transport Policy and Planning (OTP), the organisation responsible for the master plan in Section 3. In Section 4, we detail the urban transport master plan for regional cities with three case studies. We then discuss the findings of the review in Section 5 and conclude the paper in Section 6.

\section{METHODOLOGY}

This study builds on previous studies, such as Charoenmuang, D. (1998), Jaensirisak and Klungboonkrong (2007) and Jaensirisak (2006). In this study, we examine how the guideline to formulate transport plans for regional cities is implemented in Si Sa Ket, Chiang Mai, and Lampang provinces.

The selection of these regional cities was based on their size and strategic importance. Si Sa Ket and Chiang Mai cities are situated within mediumsized provinces, each with a population of over 1 million; Si Sa Ket province numbers 1.5 million and, in 2016, Chiang Mai had a population of 1.7 million (National Statistical Office (NSO), 2018). The main difference between the two lies in their strategic importance. Chiang Mai was designated as an economic hub for the Northern region with a focus on business and service sectors. In contrast, Si Sa Ket's economy is mainly based on the agriculture sector. The transport master plan of Si Sa Ket (2006) is in its first revision, whereas the Chiang Mai city master plan (2002) is in its second revision. The master plan of Lampang city (2014) is also different from the others in various aspects. Lampang city is situated within a smaller province with a population of less than 1 million. Also, it was the first master plan to undergo a monitoring and evaluation process by the OTP in a pilot scheme. We include Lampang city here to demonstrate the effort of the OTP in addressing the lack of monitoring and evaluation processes experienced by the earlier master plan.

We analyse the study process of the three master plans by employing inductive content analysis as our methodology. This method is particularly 
suitable for our subject, as there is still limited knowledge in this field (Elo \& Kyngäs, 2008). Our study is carried out at a provincial level. We review the three plans, focusing in particular on the processes adopted within the master plans, their projects, and their budget allocations. We present our study by first describing the generic steps taken to formulate a master plan. We then provide the backgrounds of each case and present the projects proposed within each plan by (i) the type of project, (ii) its time horizon, (iii) the allocation of budget, and (iv) project ownership.

The primary source of data is the official master plan. The insights provided into these processes and plans are based on the authors' involvement with the master plan formulation in the Si Sa Ket case, informal interviews with stakeholders, our previous review in Thai (Jaensirisak, 2006) and the semi-structured interviews with the Chiang Mai province Land Transport Sub-Committee (CM-LTSS) (See (Jittrapirom et al., 2017))

\section{TRANSPORT MASTER PLAN FOR REGIONAL CITIES IN THAILAND}

The legacy of transport planning in Thailand began with the first official urban transport plan in 1960. The Litchfield Plan was created for Bangkok to support its land use planning (Litchfield Whiting Bowne \& Associates, $1960)$. The practice of regional urban transport planning began some decades later, around the 1990s, as the increase in vehicle ownership in regional cities began to cause transport problems. The government issued the master plan for Chiang Mai city, the first plan for regional cities, in 1994 (Office of the Commission for the Management of Land Traffic (OCMLT), 1994). Since then, the traffic and transport master planning for regional cities has typically been carried out at the provincial level.

These processes aim to formulate a comprehensive plan to ensure the transport system is optimised and is in line with the local and national development plans. Also, it should support development of transport infrastructures that contribute toward economic development, enhance competitive advantages for investors, and encourage tourism within the province. Moreover, it should devise a transport management plan suitable for current and future land use.

The Office of Traffic and Transport Policy and Planning (OTP) is part of the Ministry of Transport. The office is responsible for the development of urban transport plans for regional cities. Founded in 2002, the OTP took over from the Office of the Commission for the Management of Land Traffic (OCMLT). It communicates directly with high-level government bodies. For instance, OTP's director is part of the Commission for the Management of Land Traffic, which proposes transport policies, plans, and related legislation to the government. It is also responsible for the national transport budget and other management issues. Moreover, it is responsible for examining transport trends and developing Intelligent Transport System (ITS) capability as well.

The Regional Transport and Traffic System Promotion Bureau is responsible for the master plan of all regional cities. It provides support to regional cities to implement and formulate their master plans, as well as the monitoring and evaluation processes. In supporting this process, the bureau has appointed six academic research institutions across Thailand as its 
knowledge centres. These centres deliver technical support and conduct the traffic and transport master plan studies for cities within their regional areas.
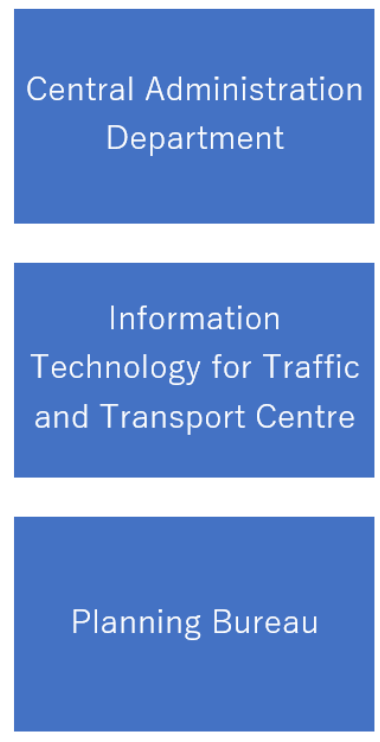
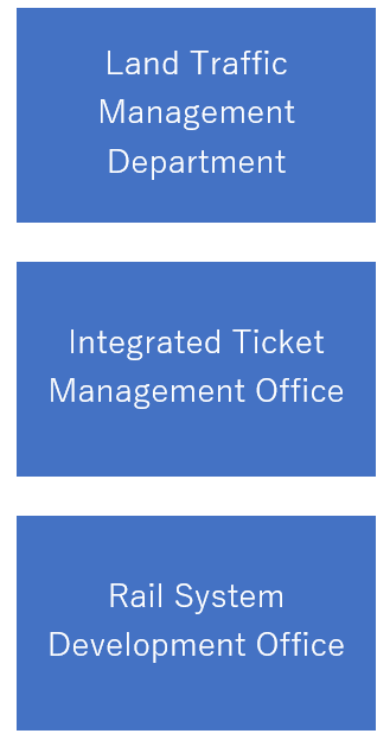
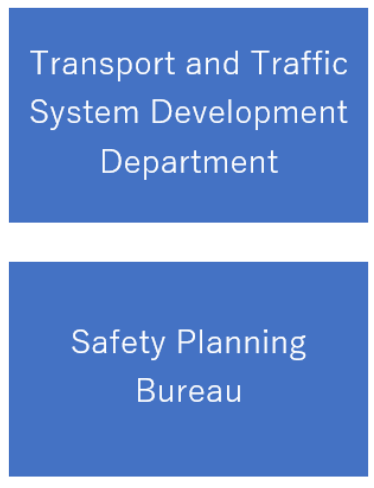

Regional Transport

and Traffic System

Promotion Bureau

Figure 1. The nine working clusters of the OTP. Source: translated from (OTP, 2018)

\section{The process and outcomes}

The overall transport master plan process of Thailand can be summarised into seven main steps as follows (Jaensirisak \& Klungboonkrong, 2007):

- Step 1 - Identify master plan objectives and ensure their coherence with related high-level documents.

- Step 2 - Establish baseline transport and land use conditions through the collection of primary and secondary data.

- Step 3 - Identify the transport problems.

- Step 4 - Develop and calibrate the baseline transport models and use them to forecast future travel demands.

- Step 5 - Use the calibrated transport model to analyse and evaluate transport projects and plans and the level of service, using the following Key Performance Indicators (KPIs): Total Vehicle-Kilometre of Travel (VKT), Vehicle-Hour of Travel (VHT), average travelling speeds, and the Volume per Capacity (V/C) ratios.

- Step 6 - Formulation of transport plans and projects, and propose them to the cabinet for adoption and implementation.

- Step 7 - Revisit each master plan to evaluate its outcomes and provide recommendations for the next master plan.

In addition to these steps, the OTP is also responsible for involving related stakeholders, such as local municipalities, provincial transport, and planning departments, and public representatives in the planning process. These participants can propose or include their transport-related projects in the master plan. The outcome of the process is presented in the form of a transport master plan report, which typically consists of background about the study area, theoretical approach and methodology, baseline conditions, analysis of mobility data, and master plan with its proposed projects. Each project is also assigned a time frame, budget, and responsible organisation(s). Each master plan considers projects under three different time frames, namely: short-term (1-2 years), medium-term (3-5 years), and long-term (6-10 years). 
After its completion, the master plan is presented to the provincial governor and adopted as a guideline for the province to develop its transport system. The master plan is non-binding because the program does not automatically include a dedicated budget to carry out the proposed projects from the central government. The responsible organisation(s) has to submit a proposal for the funding via the standard protocol. Nevertheless, the inclusion of these projects in the master plan provides an endorsement, and they are likely to receive funding from the central government. The OTP reviews and evaluates the program after some time. Currently, all regional cities in Thailand have been issued with an urban transport master plan with a handful of these cities going through the evaluation process to revise and update their master plans.

\section{CASE STUDIES}

\subsection{Case study A: Si Sa Ket Transport Master Plan (2006)}

Si Sa Ket is a north-east province of Thailand $\left(8,840 \mathrm{~km}^{2}\right)$. The urban area of Si Sa Ket (hereafter, Si Sa Ket city) covers 57 square kilometres and had a population of 44,300 in 2006. The city's transport mode share was dominated by motorcycles (66.7\%) and private cars (22.3\%). Only $5.6 \%$ of trips were made by public transport and $5.2 \%$ by walking and cycling. The main transport problems of the city at the time included: low quality of public transport services and non-motorised transport facilities, high incidence of traffic accidents, improper traffic management, congestion, and inadequate travel information.

Formulated in 2006, Si Sa Ket Transport Master Plan was carried out by the Sustainable Infrastructure Research and Development Center (SIRDC), Khon Kaen University (Office of Traffic and Transport Policy and Planning (OTP), 2006). It followed the European guidelines set out in the Prospects project (Prospects, 2000). The transferability of the guideline was assessed by Jaensirisak and Klungboonkrong (2007). The report detailed general information on the city, the conditions of land use, and the transport system. The city was suffering from several transport issues, such as traffic congestion and a lack of public transport service. These concerns provided the backdrop for the development of the master plan.

The study collected different types of primary data, such as mid-block traffic count, average vehicle speed, and roadside interviews. Additionally, secondary data from official sources, such as the traffic accident database, was collected. The two data combined to illustrate the status of the city's transport system. This data was analysed and used for the development of a four-step transport model (FSM), to predict future travel demand and to assess the impacts of different transport policies and measures (see Box 1).

At the time, the vision of Si Sa Ket city was to become a "Healthy city" and "a hub of the province in trade, service and education." The master plan proposed several objectives for the city's transport system, such as safety, efficiency, sustainability, tourism, connectivity with neighbouring countries, and economic growth. These objectives also took into consideration the visions set by the national government, the province, and the local municipality. 
The four-step transport model (FSM) is a legacy transport modelling approach dating back to the 1950s in the U.S.. It was created to forecast travel demand and highway capacity performance (i.e., traffic volume and capacity ratio and network speed). In recent years, the FSM has drawn criticisms regarding its capabilities to evaluate transport system and policy that has become more multimodal, complex, and innovative (Stopher \& Greaves, 2007; Bates, 2007; McNally, 2000). FSM also has a potential bias toward traditional transport measures, such as road widening, while discounting or even dismissing sustainable transport solutions. However, FSM is still widely used in Thailand and several developing countries for its simplicity and suitability for cities that are dominant with single-mode and motorised vehicle trips. This practice is likely to change in the future with the emerging new transport modes (e.g., ride-hailing, and ride-sharing), technology, and data availability. Also, the aim of the transport system has shifted from the predict-and-provide approach in providing capacity for vehicular movement to enhance accessibility (Leather, 2009). For example, Bangkok looks to develop an activity-based transport model for the city that utilised GPS information from the Smartphone, in-vehicle unit, and number plate recognition (Ministry of Transport (MOT), 2017).

Box 1. Four-step transport Model (FSM)

The Si Sa Ket Transport Master Plan proposed 52 projects in total. These projects can be classified into nine different types and into short (1-2 year), medium (3-5 year), and long (6-10 year) time frames. The projects proposed by the master plan are shown in Table 1 .

Table 1. Proposed projects for Si Sa Ket and Chiang Mai by type, their planned timeframe, and cost (sorted by project value)

\begin{tabular}{lcccc}
\hline & \multicolumn{2}{c}{ Si Sa Ket } & \multicolumn{2}{c}{ Chiang Mai } \\
Type of project & Project & $\begin{array}{c}\text { Value } \\
\text { No.* }\end{array}$ & Project No.** & $\begin{array}{c}\text { Value } \\
\text { mBaht }\end{array}$ \\
\hline (1) Road network & $3 / 5 / 2: 12$ & 1,331 & $0 / 0 / 0: 0$ & 0 \\
infrastructure** & $(24 \%)$ & $(69 \%)$ & $(0 \%)$ & $(0 \%)$ \\
(2) Sustainable transport & $4 / 1 / 0: 5$ & 46 & $2 / 3 / 0: 5$ & 92 \\
(3) Traffic safety, tourism, & $(10 \%)$ & $(2 \%)$ & $(12 \%)$ & $(24 \%)$ \\
and environment & $0 / 5 / 9: 15$ & 260 & $3 / 5 / 0: 8$ & 68 \\
(4) Traffic congestion & $(29 \%)^{*}$ & $(12 \%)$ & $(20 \%)$ & $(18 \%)$ \\
reduction and management & $6 / 2 / 0: 8$ & 58 & $7 / 0 / 0: 7$ & 38 \\
(5) Urban area \& land use & $(15 \%)$ & $(2 \%)$ & $(17 \%)$ & $(10 \%)$ \\
development and mang. & $0 / 0 / 0: 0$ & 0 & $3 / 3 / 3: 9$ & 27 \\
(6) Develop public transport & $(0 \%)$ & $(0 \%)$ & $(22 \%)$ & $(7 \%)$ \\
system & $0 / 0 / 0: 0$ & 0 & $1 / 0 / 1: 2$ & 21 \\
(7) Other & $(0 \%)$ & $(0 \%)$ & $(5 \%)$ & $(5 \%)$ \\
& $0 / 1 / 11: 12$ & 121 & $\mathrm{n} / \mathrm{a}$ & $\mathrm{n} / \mathrm{a}$ \\
(8) Mixed type* & $(23 \%)$ & $(5 \%)$ & & $137(36 \%)$ \\
8a) Safety \& urban & $\mathrm{n} / \mathrm{a}$ & $\mathrm{n} / \mathrm{a}$ & $5 / 3 / 2: 10(24 \%)$ & $61(16 \%)$ \\
development. & & & $2 / 2 / 2: 6(14 \%)$ & $37(10 \%)$ \\
8b) Sustainable transport & & & $2 / 1 / 0: 3(7 \%)$ & $40(10 \%)$ \\
8c) Safety \& congestion red. & & & $1 / 0 / 0: 1(3 \%)$ & \\
\hline Short / Medium / Long: Total & $13(25 \%)$ & $355(15 \%)$ & $21(51 \%)$ & $222(58 \%)$ \\
& $14(27 \%)$ & $835(36 \%)$ & $14(34 \%)$ & $150(38 \%)$ \\
(\% of total project) & $22(42 \%):$ & $1146(49 \%)$ & $6(15 \%)$ & $12(3 \%)$ \\
& $52(100 \%)$ & 2,335 & 41 & $383 *$ \\
\hline
\end{tabular}

Note: * - short/med/long: sub-total

** - two projects have no specific time frame

Exchange rate $36 \mathrm{Baht}=1 \mathrm{USD}$ 
It appears that certain types of projects are higher in number than others; road network infrastructure, traffic safety, tourism, and environment, and other projects combined to represent $76 \%$ of all projects proposed. However, the lion's share of the budget (71\%) was assigned to road network infrastructure development, which is related to private vehicle transport. In contrast, only $2 \%$ of the budget is allocated to five sustainable transport projects, which enhance non-motorised transport facilities.

The master plan placed a clear emphasis on long-term projects; 22 projects (42\% of the projects proposed) were planned for this time frame. The numbers of projects in short (25\%) and medium (27\%) time frames are comparable. Three projects were not assigned any time frame, which may be due to the uncertainty surrounding the budgeting allocations of these projects at the time. The budget allocation also shows a stronger investment in longterm projects, which received nearly $50 \%$ of the total budget. The mediumterm projects were allocated $36 \%$, and the short-term projects $15 \%$, which suggests that the short-term projects were the least capital intensive. The majority of short-term projects are sustainable transport and traffic management.

Each project in the master plan has at least one assigned owner, with certain projects having more than one (i.e., project with shared responsibility). The main actor is responsible for acquiring the project budget from the central government and for implementing the project. Table 2 shows organisations assigned as the main actors of the project, their responsibility in the plan, the number of projects assigned to them, and their budget commitment.

Table 2. Organisation responsible for proposed projects for Si Sa Ket and Chiang Mai

\begin{tabular}{|c|c|c|c|c|c|}
\hline \multirow{2}{*}{$\begin{array}{c}\text { Lead } \\
\text { organization }\end{array}$} & \multirow{2}{*}{$\begin{array}{l}\text { Responsibility in } \\
\text { this master plan }\end{array}$} & \multicolumn{2}{|c|}{ Si Sa Ket } & \multicolumn{2}{|c|}{ Chiang Mai } \\
\hline & & $\begin{array}{l}\text { No. of } \\
\text { projects }\end{array}$ & Budget & $\begin{array}{l}\text { No. of } \\
\text { projects }\end{array}$ & Budget \\
\hline $\begin{array}{l}\text { (1) Local } \\
\text { municipality }\end{array}$ & $\begin{array}{l}\text { The transport system } \\
\text { of the municipality } \\
\text { area }\end{array}$ & $\begin{array}{c}15 \\
(30 \%)\end{array}$ & $\begin{array}{l}161 \\
(7 \%)\end{array}$ & $\begin{array}{c}18 \\
(44 \%)\end{array}$ & $\begin{array}{c}209 \\
(55 \%)\end{array}$ \\
\hline (2) Multiple org* & $\mathrm{n} / \mathrm{a}$ & $\begin{array}{c}7 \\
(14 \%)\end{array}$ & $\begin{array}{c}1280 \\
(55 \%)\end{array}$ & $\begin{array}{c}6 \\
(15 \%)\end{array}$ & $\begin{array}{c}65 \\
(17 \%)\end{array}$ \\
\hline $\begin{array}{l}\text { (3) Provincial } \\
\text { Highway } \\
\text { Department }\end{array}$ & $\begin{array}{l}\text { Highway-related } \\
\text { work, liaison with } \\
\text { central government }\end{array}$ & $\begin{array}{c}3 \\
(6 \%)\end{array}$ & $\begin{array}{c}530 \\
(23 \%)\end{array}$ & $\begin{array}{c}4 \\
(10 \%)\end{array}$ & $\begin{array}{c}25 \\
(7 \%)\end{array}$ \\
\hline (4) Provincial office & $\begin{array}{l}\text { coordination and } \\
\text { decision making of } \\
\text { projects }\end{array}$ & $\begin{array}{c}1 \\
(2 \%)\end{array}$ & $\begin{array}{c}0 \\
(0 \%)\end{array}$ & $\begin{array}{c}1 \\
(2 \%)\end{array}$ & $\begin{array}{c}5 \\
(1 \%)\end{array}$ \\
\hline $\begin{array}{l}\text { (5) Department of } \\
\text { Public Works and } \\
\text { Town \& Country } \\
\text { Planning }\end{array}$ & Road maintenance & $\begin{array}{c}1 \\
(2 \%)\end{array}$ & $\begin{array}{c}8 \\
(0 \%)\end{array}$ & $\begin{array}{c}2 \\
(5 \%)\end{array}$ & $\begin{array}{c}2 \\
(1 \%)\end{array}$ \\
\hline $\begin{array}{l}\text { (6) Department of } \\
\text { Land Transport }\end{array}$ & $\begin{array}{l}\text { Develop and manage } \\
\text { public transport } \\
\text { system }\end{array}$ & $5(10 \%)$ & $\begin{array}{c}26 \\
(1 \%)\end{array}$ & $\begin{array}{c}1 \\
(2 \%)\end{array}$ & $\begin{array}{c}2 \\
(1 \%)\end{array}$ \\
\hline (7) Traffic police & $\begin{array}{l}\text { Enforcement of } \\
\text { regulation and law }\end{array}$ & $6(12 \%)$ & $\begin{array}{c}52 \\
(2 \%)\end{array}$ & $\begin{array}{c}4 \\
(10 \%)\end{array}$ & $\begin{array}{c}3 \\
(1 \%)\end{array}$ \\
\hline $\begin{array}{l}\text { (8) Others, or No } \\
\text { specific organization }\end{array}$ & $\mathrm{n} / \mathrm{a}$ & $\begin{array}{c}18 \\
(28 \%)\end{array}$ & $\begin{array}{c}487 \\
(11 \%) \\
\end{array}$ & $\begin{array}{c}5 \\
(12 \%) \\
\end{array}$ & $\begin{array}{c}73 \\
(19 \%) \\
\end{array}$ \\
\hline Total & & $\begin{array}{c}52 \\
(100 \%)\end{array}$ & $\begin{array}{c}2,335 \\
(100 \%)\end{array}$ & $\begin{array}{c}41 \\
(100 \%)\end{array}$ & $\begin{array}{c}383 \\
(100 \%)\end{array}$ \\
\hline
\end{tabular}

In total, there are 12 organisations responsible for the master plan projects. The most significant proportion of the project (30\%) is assigned to Si Sa Ket municipality, which accounted for $7 \%$ of the master plan's budget. This proportion can be increased to a maximum of $44 \%$ of the total projects, and up to $62 \%$ of the total budget if the shared projects are included. The 
single organisation that has the highest budget commitment is the Department of Highways (23\%), even though it has a small number of the project assigned to it $(6 \%)$. It should be noted that all of the projects with shared responsibility are collaborations between the Department of Highway and the municipality. This makes the two organisations responsible for projects with a combined value that accounted for $85 \%$ of the master plan budget.

\subsection{Case study B: Chiang Mai Transport Master Plan Revision 2 (2002)}

Chiang Mai is a northern province of Thailand, with an area of 20,107 square kilometres and a population of 1.66 million (2007). Its urbanised area is known as Chiang Mai Principal Area, which spans over seven districts and covers approximately 429 square kilometres. The city has been positioned as a multi-service government hub and a primary centre for various developments within the region (Charoenmuang, D. A., 2007).

The first Chiang Mai Transport Master Plan was created in 1994. It was among the earlier transport master plans for regional cities in Thailand. The OCMLT (the precursor of OTP), commissioned the Department of Civil Engineering, Chiang Mai University to revise the plan with the following objectives (Office of the Commission for the Management of Land Traffic (OCMLT), 2002):

1) to identify the trends of the city's transport system,

2) to provide integrated, convenient, fast, and safe mobility,

3) to formulate a transport management plan that accorded with the city's vision, and

4) to develop a plan and program with sufficient details to support a budget proposal.

The study is quite progressive: it refers to several international planning and transport studies; it recognises the complexity of the transport system and purports a shift away from supply-side projects (i.e., road construction) that can escalate transport problems; and it considers how social, economic, and environmental aspects connect with transport, as well as the interconnectedness between urban system entities, such as transport and land use (Office of the Commission for the Management of Land Traffic (OCMLT), 2002).

The study presents an overview of the city's transport development at the time. It reviewed and evaluated eight transport studies and projects and highlights learning points from them. It also takes stock of transport projects of different authorities and summarises relevant high-level information, such as the city's vision and national development plan. This information was used later to guide the master planning process.

The study also collected empirical data through roadside vehicle counts and mobility interviews. Several secondary data were also collected, such as vehicle ownership, public transport service, and land use pattern. A detailed transport network study, including network analysis, accident hotspot identification and parking study, was undertaken. The data collected combined to illustrate the baseline condition of the city. It was also used to construct a 4-step transport model (Transportation Improvement Planning System - TRIPS) of the city.

The study proposed a vision for the city and a set of desirable conditions for the city's mobility system, such as reduced private vehicle use and a 
comprehensive public transport network. The vision and conditions were then broken down into objectives, indicators, strategies, and measures. A set of measures were then combined to form plans and projects. Three timeframes were considered, long (10-20 years), medium (5-10 years) and short (1-5 years). The level of detail of these plans and projects was sufficient for the authority to adopt and implement them readily (see Table $1)$.

In total, 41 projects were proposed. The distribution of the projects by type also has a bias toward certain types of projects; safety, sustainable transport, and urban development projects accounted for at least $49 \%$ of the projects proposed. This proportion can increase to $73 \%$ should the mixed type projects which have at least one of these three classifications be included. Traffic safety is allocated with the highest proportion (up to 44\%) of the budget, followed by sustainable transport (up to 34\%) and urban development (up to $32 \%$ ).

The plan places emphasis on the short-term projects $(51 \%$ of the projects proposed). The medium-term projects account for $34 \%$ and the long-term projects for $15 \%$. The allocation of the budget also shows a substantial investment in short-term projects, with $58 \%$ of the total budget being allocated to projects in this time frame. The medium-term projects received $38 \%$, and the long-term projects only $3 \%$.

Also, eleven projects are classified as urgent; their immediate implementations were recommended to resolve on-going transport problems. Examples of these critical projects are public transport development, school bus system, and redesigns of accident hotspots. This classification is absent in Si Sa Ket's plan. Table 2 shows organisations assigned the ownership of the project, their responsibility in the plan, the number of projects assigned to them and their budget commitment.

In total, there are six organisations responsible for Chiang Mai's master plan projects. The municipality is responsible for the most significant proportion of the projects (44\%), which accounted for 55\% of the master plan's budget. Also, it is responsible for six more shared projects with a combined budget of 65 million baht. If these projects are included, the total budget commitment by the municipality can increase to $71 \%$ of the total budget, a much higher proportion than Si Sa Ket's.

\subsection{Case study C: Lampang Transport Master Plan evaluation (2014)}

Lampang is another province in the northern region of Thailand. It is relatively smaller than Chiang Mai, with a population of around 750,000 in 2014. Its urban area is called Lampang city. The city is in close proximity to Chiang Mai (approx. $100 \mathrm{~km}$ ) The government has assigned Lampang city as a twin city of Chiang Mai and aims to develop the two cities to complement each other.

Lampang was the first province to carry out a monitoring and evaluation study on its master plan, which was developed in 1998 and proposed 20 projects (Office of Traffic and Transport Policy and Planning (OTP), 2014). The evaluation study is an OTP's pilot project to provide feedback into the master plan study process. As this is an evaluation of the masterplan, it cannot be compared with the first two case studies. 
The master plan's monitoring was assessed using the Success Index (SI), and Stufflebeam (1983) CIPP model was used to evaluate the master plan's performance (see Table 3 ).

Table 3. Projects proposed by Lampang master plan and status in 2014

\begin{tabular}{|c|c|c|c|c|c|c|c|}
\hline \multirow[b]{2}{*}{$\begin{array}{l}\text { Project } \\
\text { Timeframe } \\
\end{array}$} & \multicolumn{4}{|c|}{ Project Status } & \multicolumn{3}{|c|}{ Budget } \\
\hline & Total & $\begin{array}{l}\text { Comp- } \\
\text { leted }\end{array}$ & $\begin{array}{l}\text { Not } \\
\text { implemented }\end{array}$ & Canceled & $\begin{array}{l}\text { Allocated } \\
\text { (mBaht) }\end{array}$ & $\begin{array}{l}\text { Utilised } \\
\text { (mBaht) }\end{array}$ & $\begin{array}{l}\% \text { of } \\
\text { total }\end{array}$ \\
\hline Short & 7 & 5 & 1 & 1 & 11.2 & 9 & $78 \%$ \\
\hline Medium & 6 & 3 & 2 & 1 & 239 & 24 & $10 \%$ \\
\hline Long & 7 & 2 & 2 & 3 & 310 & 120 & $27 \%$ \\
\hline Total & 20 & 10 & 5 & 5 & 560 & 153 & $27 \%$ \\
\hline
\end{tabular}

Ten $(50 \%)$ of the proposed projects have been implemented, five projects are not implemented, and five other projects have been cancelled. The shortterm projects have the highest completed $(71 \%)$ and budget utilisation percentages (78\%). Next are the medium time-frame projects (50\% completed and $10 \%$ budget utilisation) and the long-term projects (29\% completed and $27 \%$ budget utilisation).

The study identifies three main challenges in implementing the plan. Firstly, there was an insufficient budget available to implement the projects. These projects may even have budgets that exceeded the financial capacity of the responsible organisations. Without any financial support from the central government available, they could not be implemented. Secondly, there was a lack of technical capacity within the local organisation to implement projects. Although the OTP had made continuous effort to address this, the shortage of skills persisted (Office of Traffic and Transport Policy and Planning (OTP), 2014). These shortfalls consequentially result in the abandonment of these projects. Finally, poor project management and the lack of ownership were reported to hamper the prospects of the proposed projects.

The CIIP model provides a quantitative assessment and indicates that $50 \%$ of the implemented projects were in line with the master plan, and 50\% had challenges due to the changes in budget and political support. The model also reveals that half of the implemented projects yielded satisfactory outcomes and 7 out of 10 projects yielded tangible improvements. The projects implemented have positive impacts on the transport system.

The study highlighted the regional support cities need to devise and implement their master plans. It also recommends a closer working relationship between the OTP and local organisations, more effort in monitoring and evaluation of master plans, and the importance of developing capable personnel.

\section{DISCUSSION}

The three case studies included here (representing small- and mediumsized regional cities) present examples of how transport master plans have been formulated, implemented, and evaluated in Thailand. In this section, we discuss several distinctive features of the master plans considered in this study. 


\section{$5.1 \quad$ On the master plans}

The projects included in Si Sa Ket and Chiang Mai master plans suggest a divergence in their focuses; the $\mathrm{Si} \mathrm{Sa}$ Ket plan gave a higher priority toward infrastructure projects, whereas the Chiang Mai plan prioritised transport management and promotion of sustainable transport. The Chiang Mai plan allocated up to $34 \%$ (129 million baht) of the total budget to such projects, whereas in the Si Sa Ket case, merely 2\% (46 million baht) of its budget was allocated. The difference also reflects in their total budget sizes, as transport infrastructure projects tend to be more expensive; Chiang Mai's budget is six times smaller. Moreover, the Chiang Mai plan also lacks in road network development projects, which may have been implemented by its previous plan. Although we were not able to gain access to the first plan to confirm this matter, a study by Wannavichit (2004) shows at least seven motorway projects were implemented in Chiang Mai province before the second master plan. Additionally, two highway construction projects with a combined value of 1,330 million baht were approved before this master plan.

The differences between the master plans indicate two possible stages of master plans for Thai regional cities. The first stage of the master plan prioritises the provision of infrastructure projects (i.e., Si Sa Ket), with a larger total budget. The second stage focuses more on management and sustainable transport projects (i.e., Chiang Mai), with a relatively smaller total budget. The sequence of these stages suggests a logic that infrastructure provision should be made before changing the focus to transport management. We see the Lampang master plan as an example of how an evaluation process, such as that offered by the CIIP model, can be an add-on module to either type, rather than a stand-alone typology.

These two elements suggest a point at which a city shifts the focus of its master plan from infrastructure provision to management and sustainability promotion. What is not clear, however, is what determines the point at which this shift between the two stages should occur. How can it be identified, and at what level? Existing practices, such as a study by International Transport Forum, uses total investment in inland transport infrastructure as a percentage of GDP and net investment (\%) to report trends at the national level (International Transport Forum (ITF), 2011). At the city level, GIZ used indicators, such as road density $\left(\mathrm{km} / \mathrm{km}^{2}\right)$, road share of the urban area $(\%)$, and per Capita Road Area $\left(\mathrm{m}^{2}\right)$ (Petersen, 2004). However, the same studies also report high variations of such indicators across different cities, suggesting a challenge in establishing a 'recommended' or 'adequate' level of road infrastructure for a city.

Moreover, the urban transport system is dynamic. (Pojani \& Stead, 2015) point to the creation of additional demands for ownership of private vehicles when reliance on the construction of more roads to solve capacity problems locks a city into a motorised-future. In other words, infrastructure projects shape the long-term environment of a city, which in turn affects the travel behaviour of its citizens (Knoflacher, 2012).

The challenges in establishing the trigger point to shift the focus from one stage of the master plan to another may suggest that this decision is a political one or is driven by 'enlightened' decision-makers. However, are the decision-makers equipped with adequate tools and insights to help them initiate such change? Several studies, such as Brezina and Emberger (2017) and Jittrapirom et al. (2017) suggest otherwise; these studies argue that a large proportion of decision-makers require tools to help them understand 
the complexity of a transport system and to overcome psychological barriers that prevent them from embracing sustainable transport policy.

Finally, the way transport infrastructure is planned may change in the near future. As digitalisation is transforming the transport sector, bringing about new modes of transport, such as ride-hailing (e.g., Grab), car-sharing (e.g., Haupcar), and business models in Mobility as a Service (see (Jittrapirom et al., 2017)). These transformations may enable the public authority to avoid making costly infrastructure investments. For example, an on-demand public transport service may utilise GPS and mobile internet in smartphones to set up virtual bus stops to gather passengers anywhere. Previously, services such as Bridj (now ceased) in the US were operated on this basis. However, considerations on how different vulnerable groups, such as the elderly, can access these smart mobility services will have to be made (Jittrapirom et al., 2019).

\subsection{On the planning process}

The planning process set out by the OTP, presented in Section 3, is intended to provide a guideline for regional cities. Our analysis of the master plans finds the planning guideline to be adequate in producing the outcomes: a transport master plan. The two studies follow the guideline set out, which enables their contents and the related data to be compared with ease. Nevertheless, there are variations between them that enhance the quality of the reports. For example, the Chiang Mai plan includes references to literature on sustainability such as Meadows et al. (1972) and incorporate their findings into the planning process. Also, the plan consists of a detailed project description to help the related authority in adopting the plan. The Si Sa Ket plan is active in its stakeholder participation. It includes over 20 stakeholders in their project implementation plan. These unique features are likely to stem from the speciality of the study teams. Overall, we find that the planning process provides a guideline to standardise transport master plans with sufficient flexibility.

In our analysis, we also identify a strong influence from practices in developed countries in the plans. For instance, Si Sa Ket's plan followed a guideline set out by Prospect, a European Union-funded project; the Chiang Mai plan adopted the previous study by Japan International Cooperation Agency (JICA) (2002), a Japanese international development agency, and based the study on international literature. Finally, the evaluation framework in Lampang is based on the work of Stufflebeam (1983), a comprehensive framework for assessment that can be applied to evaluate programs, products and systems.

There may be many universal elements from these studies that can be passed to developing countries. However, a closer examination reveals challenges in transferring this know-how as several attributes set the two contexts apart, such as a more rapid pace of motorisation, differences in urban structure, discrepancies in infrastructure quality, and planning approaches (Gakenheimer, 1999; Gwilliam, 2003). Earlier work by Dimitriou (1987) purports three types of mismatches that resulted in these challenges, namely the mismatch of context, the mismatch of dominant modes of transport, and the mismatch of land use. The same study also recommended that the development of transport proposals should refer to issues unique to developing countries, such as research constraints, development policies, and institutional and political contexts. An improvement can be made by identifying common ground and differences in 
planning concepts between the two contexts, such as one carried out by Emberger et al. (2008). The study demonstrates how the transferability of the European planning process into the context of south-east Asia can be assessed.

In this study, planning and planning related documents available to the authors stand out as a challenging aspect of the research. For instance, the shift of master plan from infrastructure ( $\mathrm{Si} \mathrm{Sa} \mathrm{Ket}$ ) to sustainability promotion (Chiang Mai) might not necessarily be sequential and could be a result of other factors. Historical data and inclusion of additional case studies can help to elucidate this shift better.

\section{$5.3 \quad$ Recommendations}

There are several possible improvements to the transport planning practices in Thailand. We identify and discuss four of them here, namely motorcycle consideration, tools for planning, uncertainty in planning, and lack of resources for implementation.

Firstly, the planning process should place greater emphasis on other modes of transport, including the motorcycle. The two plans focus on projects and measures that address transport issues related to cars, while more than $50 \%$ of vehicles in the cities are motorcycles (Jittrapirom, Knoflacher, \& Mailer, 2017). While car-related policy and measures may apply to the motorcycle, increased attention to the latter mode can decrease the vulnerability of the motorised two-wheeler. Several countries with a similar level of the motorcycles, such as Taiwan, have implemented policies and measures focused on motorcycles successfully (Hsu, Sadullah, \& Nguyen, 2003).

Secondly, a reconsideration of current planning tools should be made. For instance, the study teams of the two master plans employed the traditional Four-Stage Model (FSM), which has received criticisms over the recent years - see Box 1. Land Use and Transport Interaction (LUTI) or an activity-based model, on the other hand, simulates the interaction between transport and other entities (e.g., land use) and allows modelling of more complex mobility behaviour and non-motorised transport modes. Similarly, the application of the CIPP framework illustrates a limitation on reporting effects of a transport project. It is therefore essential to evaluate the current tools to ensure it is fit for purpose.

Thirdly, the planning time horizon and its process should take into account uncertainty. The typical time horizon of these master plans is ten years, which may be adequate for a city in the developed world with the incremental growth of vehicles in a stable political environment. In the case of a city such as Chiang Mai, the growth of vehicle numbers can be as high as $7 \%$ per year with a possibility of changes in the direction of political wind every two years on average; the country has seen a change in its government 16 times over the last 30 years. Although the current practise enables the local authority to alter its plan when required, embedding adaptation as part of the process can bring about benefits, such as increased likelihood to implement the plan successfully. Planning schemes such as the Dynamic Adaptive Policymaking (DAP) scheme enables policymakers to deal with uncertainties surrounding the policy formulation process (Jittrapirom et al., 2018; Walker, Rahman, \& Cave, 2001). Also, as it is built on the principle that complete information about a system is unattainable, DAP helps to move away from trend-based predictions. Instead, it focuses on utilising available information in making a robust policy that is capable of dealing 
with uncertain vulnerabilities while at the same time taking advantage of any arising beneficial effects. Moreover, the built-in monitoring process of DAP can contribute towards the efforts made to monitor the implementation of the plan (See (Jittrapirom et al., 2018) for DAP application).

Finally, insufficient financial support and human resources are the two reasons why many projects in the Lampang master plan did not take place. Our analysis also shows how large sums of financial and human resource burdens were placed on the two local municipalities to finance and implement the projects included in the master plans. Although such resource commitments are spread out over the period of the master plan, it may result in the delay or cancellation of these projects, as demonstrated by the Lampang case. This challenge also links to the implementation aspects of the plan. A possible improvement can be made by exploring alternative sources of financial support, such as allocation of financial resources from the central government to the project proposed in the master plan or an open invitation for investment from the private sector. The latter is currently being explored as an instrument for infrastructure investments in ten regional cities, including Chiang Mai (Thansettakij, 2017).

Future studies can also examine how governance processes in developing countries, such as Thailand, influence the implementation of transport plans and in what way legislative mechanisms can ensure successful implementation of long-term transport projects. Our study suggests several improvements to the planning process, such as consideration to other modes of transport, and continuous, robust monitoring and evaluation, and incorporation of the adaptive planning framework that explicitly deal with uncertainty. These enhancements can help to ensure that approved projects are carried out efficiently and effectively.

\section{CONCLUSION}

Thailand's transport master plans for regional cities have proven to be a valuable exercise. They provide an opportunity to pool data and resources to gather transport-related data and information that would otherwise not have been collected by local authorities. It also enables the interactions and knowledge exchange between local authorities and their research institutes, thus building their capacities. The masterplans also provide a snapshot of the local conditions concerning transport, land use, socio-demographics, and environmental aspects of each city. They also provide a clear transport development guideline within a specific time frame. Also, the master plans are readily available to the public.

These masterplans have been used to support budget proposals by local governments and by the central government to aid with its budget allocations. Despite these transferable benefits, several improvements to the process have been identified in this study, such as the allocation of resources to ensure the plan can be implemented. The analysis also identifies two possible stages of master plans, which can be further refined by the inclusion of additional case studies from Thailand and beyond. Moreover, additional information from practitioners and stakeholders involved in the process may provide further insights into these fields. In particular, the new possibility of appealing to the private sector to invest in public infrastructure may alter these existing dynamics in a significant way. 


\section{ACKNOWLEDGEMENT}

We thank Philip Blant and Paddy Lloyd for their invaluable supports with the revisions of this paper. We are also grateful for the two anonymous reviewers who provided useful comments that helped to improve the manuscript.

\section{REFERENCES}

Banister, D. (2001). "Transport Planning". In Kenneth, J. B. \& David, A. H. (Eds.), Handbook of Transport Systems and Traffic Control (Vol. 3, pp. 9-19): Emerald Group Publishing Limited. doi: https://doi.org/10.1108/9781615832460-002.

Bates, J. (2007). "History of Demand Modelling". In David, A. H. \& Kenneth, J. B. (Eds.), Handbook of Transport Modelling (Vol. 1, pp. 11-34): Emerald Group Publishing Limited. doi: https://doi.org/10.1108/9780857245670-002.

Black, W. R. (2010). Sustainable Transportation: Problems and Solutions. New York: Guilford Press.

Brezina, T., \& Emberger, G. (2017, Sept 12-14). "Changing Structures Induce Changing Behaviour: Streetscape Revitalisation and Human Mobility". Proceedings of 22nd International Conference on Urban Planning, Regional Development and Information Society - GeoMultimedia 2017, Vienna; Austria, pp. 677-684. Retrieved from https://www.corp.at/archive/CORP2017 28.pdf.

Charoenmuang, D. (1998). City and City Planning in Thailand: Case of Chiang Mai. Urban Studies Section, Social Research Institute, Chiang Mai University.

Charoenmuang, D. A. (2007). Sustainable Cities in Chiang Mai: A Case of a City in a Valley. Chiang Mai, Thailand: Chiang Mai University.

Daniere, A. G. (1995). "Transportation Planning and Implementation in Cities of the Third World: The Case of Bangkok". Environment and Planning C: Government and Policy, 13(1), 25-45. doi: https://doi.org/10.1068/c130025.

Dimitriou, H. (1987). "The Urban Transport Planning Process and Its Derivatives: A Critical Review of Their Evolution and Appropriateness to Third World Cities". Hongkong: Centre of Urban Studies and Urban Planning, University of Hongkong.

Elo, S., \& Kyngäs, H. (2008). "The Qualitative Content Analysis Process". Journal of Advanced Nursing, 62(1), 107-115. doi: https://doi.org/10.1111/j.13652648.2007.04569.x.

Emberger, G., Pfaffenbichler, P., Jaensirisak, S., \& Timms, P. (2008). "“Ideal” DecisionMaking Processes for Transport Planning: A Comparison between Europe and South East Asia". Transport Policy, 15(6), 341-349. doi: https://doi.org/10.1016/j.tranpol.2008.12.009.

Figueroa, O. (2013). "Four Decades of Changing Transport Policy in Santiago, Chile". Research in Transportation Economics, 40(1), 87-95. doi: https://doi.org/10.1016/j.retrec.2012.06.031.

Gakenheimer, R. (1999). "Urban Mobility in the Developing World". Transportation Research Part A: Policy and Practice, 33(7), 671-689. doi: https://doi.org/10.1016/S09658564(99)00005-1.

Geerlings, H., \& Stead, D. (2003). "The Integration of Land Use Planning, Transport and Environment in European Policy and Research". Transport Policy, 10(3), 187-196. doi: https://doi.org/10.1016/S0967-070X(03)00020-9.

Greene, D. L., \& Wegener, M. (1997). "Sustainable Transport". Journal of Transport Geography, 5(3), 177-190. doi: https://doi.org/10.1016/S0966-6923(97)00013-6.

Gwilliam, K. (2003). "Urban Transport in Developing Countries". Transport Reviews, 23(2), 197-216. doi: https://doi.org/10.1080/01441640309893.

Hsu, T.-P., Sadullah, A. F. M., \& Nguyen, D. X. (2003). "A Comparison Study on Motorcycle Traffic Development in Some Asian Countries-Case of Taiwan, Malaysia and Vietnam". $\quad$ Retrieved from http://www.easts.info/activities/icra/2001/ICRAComparisonStudyMotorcycleDevelopment.pdf.

International Transport Forum (ITF). (2011). "Trends in Transport Infrastructure Investment 1995-2009". Paris: Organisation for Economic Co-operation and Development.

Jaensirisak, S. (2006). "Summary of the Thailand Transport Master Plans". Proceedings of 3rd National Transport Conference, Thailand. 
Jaensirisak, S. (2008). "Working Paper: Development of Bangkok Mass Rapid Transit". Ubon Ratchathani: Ubon Ratchathani University.

Jaensirisak, S., \& Klungboonkrong, P. (2007). "Lessons from Application of the "Ideal" Transport Planning Process to Thailand". KKU Engineering Journal, 34(5), 517-533.

Japan International Cooperation Agency (JICA). (2002). "The Study on Improvement of Road Traffic Environment in Chiang Mai City in the Kingdom of Thailand : Final Report".

Jittrapirom, P., Caiati, V., Feneri, A.-M., Ebrahimigharehbaghi, S., González, M. J. A., \& Narayan, J. (2017). "Mobility as a Service: A Critical Review of Definitions, Assessments of Schemes, and Key Challenges". 2017, 2(2), 13. doi: http://dx.doi.org/10.17645/up.v2i2.931.

Jittrapirom, P., Knoflacher, H., \& Mailer, M. (2017). "The Conundrum of the Motorcycle in the Mix of Sustainable Urban Transport". Transportation Research Procedia, 25, 48694890. doi: https://doi.org/10.1016/j.trpro.2017.05.365.

Jittrapirom, P., Marchau, V., van der Heijden, R., \& Meurs, H. (2018). "Dynamic Adaptive Policymaking for Implementing Mobility-as-a Service (Maas)". Research in Transportation Business \& Management, 27, 46-55. doi: https://doi.org/10.1016/j.rtbm.2018.07.001.

Jittrapirom, P., van Neerven, W., Martens, K., Trampe, D., \& Meurs, H. (2019). "The Dutch Elderly's Preferences toward a Smart Demand-Responsive Transport Service". Research in Transportation Business \& Management, 30, 100383. doi: https://doi.org/10.1016/j.rtbm.2019.100383.

Knoflacher, H. (2012). Grundlagen Der Verkehrs- Und Siedlungsplanung. Vienna: Böhlau Verlag.

KonSULT. (2005). "What Is Konsult?". Retrieved from http://www.konsult.leeds.ac.uk/what-is-konsult/ on March 15, 2018.

Leather, J. (2009). "Changing Course: A New Paradigm for Sustainable Urban Transport". Manila, Philippines: Korea: Asian Development Bank (ADB). Retrieved from https://www.adb.org/sites/default/files/transport-manual.pdf.

Litchfield Whiting Bowne \& Associates. (1960). Greater Bangkok Plan. Ministry of the Interior, United States Operations Mission to Thailand. Retrieved from https://books.google.nl/books?id=yddiNAAACAAJ.

May, A. D. (1991). "Integrated Transport Strategies: A New Approach to Urban Transport Policy Formulation in the U.K". Transport Reviews, 11(3), 223-247. doi: https://doi.org/10.1080/01441649108716786.

McNally, M. (2000). "The Four-Step Model". In Hensher, D. A. \& Button, K. J. (Eds.), Handbook of Transport Modeling: Pergamon. Retrieved from https://escholarship.org/uc/item/0r75311t.

Meadows, D., Meadows, D., Randers, J., \& Behrens, W. (1972). The Limits to Growth. Universe Books.

Ministry of Transport (MOT). (2017). "Digital Transport 2021 Value Creation for Economic \& Social Development". Bangkok: Ministry of Transport. Retrieved from http://www.otp.go.th/uploads/tiny_uploads/PDF/2560-11/25601116PlanDEMOT2021.pdf.

Miyamoto, K., Udomsri, R., Sathyaprasad, S., \& Ren, F. (1996). "A Decision Support System for Integrating Land Use, Transport and Environmental Planning in Developing Metropolises". Computers, Environment and Urban Systems, 20(4), 327-338. doi: https://doi.org/10.1016/S0198-9715(97)00009-4.

Nakamura, H., Hayashi, Y., \& May, A. D. (Eds.). (2004). Urban Transport and the Environment: An International Perspective. Bingley, UK: Emerald Group Publishing Limited.

National Statistical Office (NSO). (2018). "National Population Statistic". Retrieved from http://web.nso.go.th/.

Office of the Commission for the Management of Land Traffic (OCMLT). (1994). "Master Plan for the Management of Traffic in the City of Chiang Mai, Revision 1". Chiang Mai: Office of the Commission for the Management of Land Traffic.

Office of the Commission for the Management of Land Traffic (OCMLT). (2002). "Chiang Mai Transport Master Plan Revision 2". Bangkok: Office of the Commission for the Management of Land Traffic.

Office of Traffic and Transport Policy and Planning (OTP). (2006). "A Study on Traffic and Tranportation Master Plan for Regional Cities - Sri Sa Ket Province". Bangkok: Office of Traffic and Transport Policy and Planning.

Office of Traffic and Transport Policy and Planning (OTP). (2014). "Evaluation of Lampang Transport Master Plan". Bangkok: Office of Traffic and Transport Policy and Planning. 
Petersen, R. (2004). "Land Use Planning and Urban Transport". Sustainable Transport: A Sourcebook for Policy-Makers in Developing Cities Module $2 a$.

Pojani, D., \& Stead, D. (2015). "Sustainable Urban Transport in the Developing World: Beyond Megacities". Sustainability, 7(6), 7784-7805. doi: https://doi.org/10.3390/su7067784.

Prospects. (2000). "Prospects Project". Retrieved from http://www.fvv.tuwien.ac.at/forschung/projekte/international-projects/prospects2000.html.

Shepherd, S. P., Zhang, X., Emberger, G., Hudson, M., May, A. D., \& Paulley, N. (2006). "Designing Optimal Urban Transport Strategies: The Role of Individual Policy Instruments and the Impact of Financial Constraints". Transport Policy, 13(1), 49-65. doi: https://doi.org/10.1016/j.tranpol.2005.08.002.

Stopher, P. R., \& Greaves, S. P. (2007). "Household Travel Surveys: Where Are We Going?". Transportation Research Part A: Policy and Practice, 41(5), 367-381. doi: https://doi.org/10.1016/j.tra.2006.09.005.

Stufflebeam, D. L. (1983). "The Cipp Model for Program Evaluation". In Madaus, G. F., Scriven, M. S., \& Stufflebeam, D. L. (Eds.), Evaluation Models: Viewpoints on Educational and Human Services Evaluation (pp. 117-141). Dordrecht: Springer Netherlands. doi: https://doi.org/10.1007/978-94-009-6669-7_7.

Thansettakij. (2017). "City Development Company Starts in 10 Regional City". Retrieved from http://www.thansettakij.com/content/232641 on March 14, 2018.

Ülengin, F., Önsel, Ş., İlker Topçu, Y., Aktaş, E., \& Kabak, Ö. (2007). "An Integrated Transportation Decision Support System for Transportation Policy Decisions: The Case of Turkey". Transportation Research Part A: Policy and Practice, 41(1), 80-97. doi: https://doi.org/10.1016/j.tra.2006.05.010.

Un-Habitat. (2013). "Planning and Design for Sustainable Urban Mobility Global Report on Human Settlements - Global Report on Human Settlements 2013". Taylor \& Francis. Retrieved from https://unhabitat.org/sites/default/files/download-managerfiles/Planning\%20and\%20Design\%20for\%20Sustainable\%20Urban\%20Mobility.pdf.

Volpe Martincus, C., Carballo, J., \& Cusolito, A. (2017). "Roads, Exports and Employment: Evidence from a Developing Country". Journal of Development Economics, 125, 21-39. doi: https://doi.org/10.1016/j.jdeveco.2016.10.002.

Walker, W. E., Rahman, S. A., \& Cave, J. (2001). "Adaptive Policies, Policy Analysis, and Policy-Making". European Journal of Operational Research, 128(2), 282-289. doi: https://doi.org/10.1016/S0377-2217(00)00071-0.

Walters, J. (2013). "Overview of Public Transport Policy Developments in South Africa". Research in Transportation Economics, 39(1), 34-45. doi: https://doi.org/10.1016/j.retrec.2012.05.021.

Wannavichit, N. (2004). "Transportation Development and Land Use Dynamics in Chiang Mai Urban Fringe". Chiang Mai University.

World Health Organization. (2015). Global Status Report on Road Safety 2015. Geneva, Switzerland: World Health Organization.

World Health Organization. (2018). "Global Status Report on Road Safety 2018". Geneva, Switzerland: World Health Organization.

Zhang, X., Paulley, N., Hudson, M., \& Rhys-Tyler, G. (2006). "A Method for the Design of Optimal Transport Strategies". Transport Policy, 13(4), 329-338. doi: https://doi.org/10.1016/j.tranpol.2005.12.006. 